\title{
Patterns of Dietary Iron Intake, Iron Status, and Predictors of Haemoglobin Levels among Early Adolescents in a Rural Ghanaian District
}

\author{
Michael Akenteng Wiafe (iD, Charles Apprey, and Reginald Adjetey Annan \\ Department of Biochemistry and Biotechnology, Kwame Nkrumah University of Science and Technology, Private Mail Bag, \\ Kumasi, Ghana \\ Correspondence should be addressed to Michael Akenteng Wiafe; mwiafeakenten@yahoo.ca
}

Received 8 July 2020; Revised 21 October 2020; Accepted 16 December 2020; Published 24 December 2020

Academic Editor: Abdah Md Akim

Copyright (c) 2020 Michael Akenteng Wiafe et al. This is an open access article distributed under the Creative Commons Attribution License, which permits unrestricted use, distribution, and reproduction in any medium, provided the original work is properly cited.

\begin{abstract}
Introduction. Early adolescents are vulnerable to anaemia due to lean body mass and menarche. The study assessed patterns of dietary iron intake, iron status, and predictors of anaemia among early adolescents. Method. One hundred and thirty-seven early adolescents were randomly selected in a rural district in Ghana. Multiple-pass 24-hour recall, iron food frequency questionnaire consisting of 27 food items, and semistructured questionnaire were administered. Variables include sociodemographics, dietary factors, and laboratory investigation including haemoglobin, ferritin, and C-reactive protein examination. Statistical Package for the Social Sciences (SPSS) software was used to calculate odds ratio and perform Mann-Whitney U test, chi-square $\left(\mathrm{X}^{2}\right)$ test, exploratory factor analysis, and partial correlation $(r)$ tests. Results. Participants had mean age of 11.5 years. Three iron dietary patterns explaining $28.7 \%$ of the total variance were identified: iron dietary pattern 1 (11\%) composed of iron-rich, iron-enhancing, and iron-inhibiting foods; iron dietary pattern 2 (9.9\%) comprised of iron-rich, iron-enhancing, and non-iron-inhibiting foods; and iron dietary pattern 3 (7.1\%) consisting of stinging nettle, iron-inhibiting foods, non-iron-enhancing foods, noncocoyam leaves, and non-turkey berries. Meal skipping $\left(X^{2}=5.7, p<0.05\right)$, times of eating a day $\left(X^{2}=12.6, p<0.05\right)$, and guardian educational status $\left(X^{2}=6.7, p<0.05\right)$ significantly affected dietary iron intake. Anaemia was associated with meal skipping $(\beta=0.367, p>0.05)$, snacking $(\beta=0.484, p>0.05)$, and junior high school (JHS) education $(\beta=0.544, p>0.05)$. Partial correlation showed statistically significant relationship between iron dietary pattern 1 and dietary iron $(r=-0.234, p<0.01)$, iron dietary pattern 2 and dietary iron $(r=-0.198, p<0.05)$, iron dietary pattern 2 and vitamin $C(r=-0.201, p<0.05)$, and haemoglobin and ferritin $(r=-0.178, p<0.05)$. Conclusion. Meal skipping, guardian educational status, and number of times of eating a day were significantly associated with dietary iron intake. Meal skipping, snacking, and adolescents with JHS education were positively associated with anaemia.
\end{abstract}

\section{Introduction}

World Health Organization (WHO) defines adolescence as a period between 10 to 19 years of the life cycle, categorised into early, middle, and late adolescence, with about threequarters living in developing countries $[1,2]$. Early adolescents, particularly females, are among those at high risk of iron deficiency due to menarche, growth spurt, and other physiological development [3-6]. A study has recommended the consideration of iron deficiency anaemia as one of the key nutritional status indicators in adolescence [7]. Iron is relevant for immunity, cognitive function, behaviour, physical activity, and lean body mass development [8-12].

Dietary iron is obtained from a restricted number of animal and plant sources of food, mostly from meat, liver, legumes, and nuts [13]. Non-haem iron sources such as cereals and grains products were the main dietary iron intake of the studied population in Spain [14]. In developing countries, plant-based food forms a major part of the diet with limited quantities from animal sources, and increased 
consumption of western diet worsens the adolescent micronutrient plight $[15,16]$. Insufficient dietary iron intake contributed inversely to iron status indicators such as serum ferritin, transferrin saturation, and total iron-binding capacity [17].

The prevalence of anaemia among school age children (5-14 years) is estimated to be $25.4 \%$ globally [18]. In least developed countries, about $27 \%$ of adolescents suffered from anaemia related to iron deficiency [19]. In Nepal, a nationwide study on anaemia among adolescents showed that $38 \%$ of females and $24 \%$ of males had iron deficiency anaemia [20]. In the literature, a study showed that $24 \%$ of adolescent girls (10-19 years) and 13\% of adolescent boys were anaemic in Ghana [21]. The data shows that prevalence of anaemia in adolescents is a public health concern. Much research has not been done about the prevalence of anaemia and its contributory factors among early adolescents in Ghana.

Adolescent health is influenced by prenatal and early childhood development [22]. Abuse of alcohol, sexual promiscuity, attention disorders, and lawlessness in adolescence have been linked to childhood anaemia [23]. Adolescents having iron deficiency with or without anaemia showed low scholastic, verbal learning, attention, mental balance, and recognition performance [24]. Low birth weight and low Apgar score have been the pregnancy outcomes of pregnant adolescents with abnormal iron status [25].

Low levels of guardian education, low socioeconomic status, being female adolescent, early age of menarche, prolonged and excessive blood loss during menstruation, low intake of iron-fortified foods, inadequate intake of haem foods and iron-enhancers, and high intake of iron-inhibitors are the drivers of iron deficiency anaemia in adolescents [26-32]. Poor dietary exploration, worm infestations, meal skipping, illiteracy, seeking peer approval, and concern for body shape predispose adolescents to iron malnutrition particularly those living in least developed countries [33-36]. The present study aimed to identify patterns of dietary iron intake, iron status, and predictors of anaemia among early adolescents in a rural district in Ghana.

\section{Materials and Methods}

2.1. Study Design. A cross-sectional study was conducted at the Asante Akim South Municipality. The study protocol was approved by the Committee on Human Research Publication and Ethics at Kwame Nkrumah University of Science and Technology, Kumasi, and permission was also given by the Asante Akim South Municipal Health Directorate.

2.2. Participants. Early adolescents (10-14 years) were approached in the municipality for the study. One hundred and thirty-seven participants gave their assent and guardians gave their consent after the objective of the study was explained in the language they understand. Participants and guardians signed an informed consent form. Those who could not sign were made to use thumbprint.
2.3. Data Collection. One hundred and thirty-seven participants responded to the dietary questionnaire. One participant failed to return to the phlebotomy site for blood sample collection but responded to the questionnaire. Five participants had their haemoglobin checked: one had inadequate serum for the analysis of ferritin and C-reactive protein; four participants' samples were double labelled and therefore removed from the analysis. Thus, a total of 136 participants had their haemoglobin checked, and 131 had their ferritin and C-reactive protein analysed.

2.4. Dietary Survey. Nutritionists and dieticians were trained to use 24-hour recall to collect dietary data, on one weekend and two weekdays. Participants were shown food models to estimate how much they consumed, and results were documented. All the foods eaten were converted into grams, and total dietary iron intake was analysed using the nutrient analysis template of foods in Ghana. Adequate dietary iron was defined as $8 \mathrm{mg}$ /day as recommended by the National Academy of Sciences [37].

2.5. Dietary Patterns. Iron Food Frequency Questionnaire contained 27 food items: 14 iron-rich foods; 8 iron-enhancing foods; 5 iron-inhibiting foods. The questionnaire had the following options for participants to choose from: a. daily; b. weekly; c. monthly; d. occasionally/never.

2.6. Blood Analysis. Venous blood samples of participants were analysed for ferritin, C-reactive protein, and haemoglobin (Hb). Human ferritin Elisa test kit (Enzyme Immunoassay test kit, catalogue number: 10601) was used for the ferritin analysis, and high sensitivity C-reactive protein (Enzyme Immunoassay test kit, catalogue number: 10603) was used for C-reactive protein at the Clinical Analysis Laboratory at the Kwame Nkrumah University of Science and Technology, Kumasi.

2.6.1. Procedure for Human Ferritin Analysis. Twenty (20) microlitres $(\mu \mathrm{L})$ of samples, standard specimens, and controls were appropriately dispensed into wells. One hundred (100) microlitres $(\mu \mathrm{L})$ of enzyme conjugate reagent was dispensed into each well. The content in the wells were thoroughly mixed for thirty (30) seconds. The wells were incubated at room temperature $\left(18-22^{\circ} \mathrm{C}\right)$ for sixty $(60)$ minutes. The incubated mixture was removed by flicking plate content in a waste container. The microlitre wells were rinsed and flicked five (5) times with washing buffer (1X). The wells were stroked sharply onto absorbent paper to remove all residual water droplets. $100 \mu \mathrm{L}$ of tetramethylbenzidine (TMB) substrate was dispensed into each well and was gently mixed for five (5) seconds. The content was incubated at room temperature in the dark for twenty (20) minutes. The reaction was stopped by adding $100 \mu \mathrm{L}$ of stop solution to each well. Each was gently mixed for thirty (30) seconds, and it was ensured that all the blue colour changed to yellow colour completely. The optical density was read at $450 \mathrm{~nm}$ with a microlitre reader within fifteen minutes. 
2.6.2. Procedure for C-Reactive Protein Analysis. Participants serums and control serums were diluted with distilled water (100-fold) prior to use. Fifty (50) $\mu \mathrm{L}$ of undiluted CRP standards, diluted specimens, and diluted controls were dispensed into appropriate wells. $50 \mu \mathrm{L}$ of sample diluent was dispensed into each well and thoroughly mixed for 30 seconds. It was ensured that the content was mixed completely. The mixture was incubated at room temperature $\left(18-22^{\circ} \mathrm{C}\right)$ for thirty (30) minutes. The incubated mixture was removed by flicking plate contents into a waste container. The microlitre wells were rinsed and flicked 5 times with washing buffer (1X). The wells were stroked sharply onto absorbent paper to remove all residual water droplets. One hundred (100) $\mu \mathrm{L}$ CRP enzyme conjugate reagent was dispensed into each well. The content was thoroughly mixed for 30 seconds and incubated at room temperature $\left(18-22^{\circ} \mathrm{C}\right)$ for 30 minutes. The incubated mixture was removed by flicking plate contents into a waste container. The microtiter wells were rinsed and flicked five times with washing buffer (1X). The wells were stroked sharply onto absorbent paper or paper towels to remove all residual water droplets. $100 \mu \mathrm{L}$ tetramethylbenzidine (TMB) reagent was dispensed into each well and gently mixed for five (5) seconds. The mixture was incubated at room temperature for 30 minutes. $100 \mu \mathrm{L}$ of stop solution was added to each well to stop the reaction. The content was gently mixed for 30 seconds to ensure that all the blue colour changed to yellow colour completely. A microtiter well reader at absorbance of $450 \mathrm{~nm}$ was used to read the results within fifteen (15) minutes.

2.6.3. Procedure for Haemoglobin Testing. Haemoglobin $\mathrm{Hb}$ was determined using HemoCue $\mathrm{Hb} 301$ analyser (HemoCue AB, SE-262 23, Ängelholm, Sweden) on the field. The microcuvette (301) was filled automatically after placing it in a drop of blood. Lint-free wipe was used to wipe off excess blood on the microcuvette. The open end of the microcuvette was not touched and also checked for air bubbles. The filled microcuvette was placed in the holder, and the cuvette holder was gently touched to automatically slide it to the measuring position. The $\mathrm{Hb}$ result was shown within about ten (10) seconds, and it was documented. Anaemia was defined as $\mathrm{Hb}$ less than $11 \mathrm{~g} / \mathrm{dL}$ as given by the manufacturer's manual.

2.7. Statistical Analysis. Statistical Package for the Social Sciences (SPSS) (IBM Corp. Released 2017. IBM SPSS Statistics for Windows, Version 25.0. Armonk, NY: IBM Corp) was used for all the statistical analyses. Descriptive statistics were used to analyse sociodemographic characteristics and dietary factors presented in frequency, percentages, and charts. Continuous nonparametric data was presented in the median (minimum and maximum) and independent samples. Mann-Whitney $U$ test was used to analyse haemoglobin and ferritin status. Chi-square test was done to assess the relationship between the dietary iron intake, sociodemographic factors, and dietary factors. Exploratory factor analysis with principal component was used to obtain the iron dietary patterns with eleven components extracted. Three dietary patterns were retained based on eigenvalues greater than one, loading factor of \pm 0.3 , and scree plot. Being adjusted for age and gender, the partial correlation was employed to assess the relationship and direction of iron dietary pattern and biochemical markers. Binary logistics regression was used to predict the relationship between sociodemographic factors, such as gender, level of education, and guardian education status, and dietary factors, such as meal skipping, breakfast, snacking, dietary iron and vitamin $\mathrm{C}$ intake, and haemoglobin status. The sociodemographic and dietary factors were the independent variables, and haemoglobin, ferritin, and C-reactive protein were the dependent variables.

\section{Results}

3.1. Descriptive Statistics. A total of 137 early adolescents (10-14 years) voluntarily participated in the study, with $50.4 \%$ being males and $49.6 \%$ females. The majority of the respondents were aged eleven $(30.7 \%)$, followed by thirteen (24.1\%), twelve (23.3\%), and ten (21.9\%) years. Participants had mean age of $11.5 \pm 1.1$ years. Among the participants, $70.1 \%$ were in primary school and $29.9 \%$ were in junior high school (JHS); $77.9 \%$ and $22.1 \%$ of guardians had formal and nonformal education, respectively.

\subsection{Meal Patterns of Study Participants. More males (68.1\%)} had adequate dietary iron intake than females (57.4\%) (Figure 1). A higher number of participants whose guardians had formal education (70.9\%) had adequate intake of dietary iron than those without formal education (29.1\%). Most of the participants ate three times daily $(71.5 \%)$, followed by four or more times (14.6\%) and twice (13.9\%). In descending order of adequate dietary iron intake, $68.6 \%, 22.1 \%$, and $9.3 \%$ ate three times, four or more times, and twice daily, respectively. Meal skipping was popular representing 55.5\% as against non-meal skipping $45.5 \%$. Most of the non-meal skippers (52.3\%) had adequate dietary iron intake compared with meal skippers (47.7\%). Lunch (75\%) was the most skipped meal by participants, followed by breakfast (19.7\%) and dinner (5.3\%). More of the lunch skippers (73.2\%) had adequate dietary iron intake than the other meals skippers. Among the adolescents who took breakfast, the majority $(86 \%)$ had adequate dietary iron intake as against inadequate intake (82.4\%). Seventy-three percent (73\%) of participants snacked daily and $27 \%$ did not. The majority of snackers had adequate intake of dietary iron compared with non-snackers (72.1\% versus $27.9 \%)$ (Table 1 ).

\subsection{Association between Iron Intake, Dietary Factors, and} Sociodemographic Characteristics. Pearson chi-square showed statistically insignificant $(p>0.05)$ relationship between dietary iron intake and factors such as age $\left(X^{2}=0.584\right)$, participants' level of education $\left(X^{2}=0.919\right)$, type of meal skipped $\left(X^{2}=0.306\right)$, breakfast intake $\left(X^{2}=0.627\right)$, and snacking $\left(X^{2}=0.843\right)$. Pearson chi-square analysis showed that guardian educational status $\left(X^{2}=6.7\right.$, 


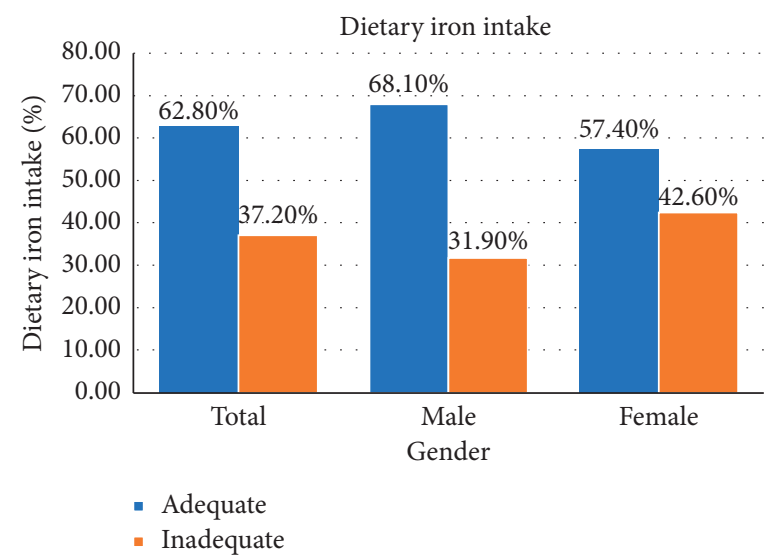

FIGURE 1: Dietary iron status by gender.

TABLE 1: Sociodemographic factors, dietary factors, and dietary iron intake.

\begin{tabular}{|c|c|c|c|c|c|c|}
\hline \multirow{2}{*}{ Total variables } & \multirow{2}{*}{ Mean \pm SD } & \multirow{2}{*}{$N(\%)$} & \multicolumn{2}{|c|}{ Dietary iron intake } & \multirow{2}{*}{$X^{2}$} & \multirow[b]{2}{*}{$p$ value } \\
\hline & & & Adequate & Inadequate & & \\
\hline Age (years) & $11.5 \pm 1.1$ & & & & 1.9 & 0.584 \\
\hline 10 & & $30(21.9)$ & $19(22.2)$ & $11(21.6)$ & & \\
\hline 11 & & $42(30.7)$ & $23(26.7)$ & $19(37.3)$ & & \\
\hline 12 & & $32(23.3)$ & $21(24.4)$ & $11(21.6)$ & & \\
\hline 13 & & $33(24.1)$ & $23(26.7)$ & $10(19.5)$ & & \\
\hline \multicolumn{7}{|l|}{ Level of education } \\
\hline Participants & & & & & 0.0 & 0.919 \\
\hline Primary & & $96(70.1)$ & $60(69.8)$ & $36(70.6)$ & & \\
\hline Junior high school & & $41(29.9)$ & $26(30.2)$ & $15(29.4)$ & & \\
\hline Guardian & & & & & 6.7 & 0.010 \\
\hline Formal education & & $106(77.9)$ & $61(70.9)$ & $45(90.0)$ & & \\
\hline Nonformal education & & $30(22.1)$ & $25(29.1)$ & $5(10.0)$ & & \\
\hline Guardian & & & & & 3.5 & 0.319 \\
\hline Both parents & & $88(64.2)$ & $59(68.6)$ & $29(56.9)$ & & \\
\hline Mother & & $24(17.5)$ & $12(14.0)$ & $12(23.5)$ & & \\
\hline Father & & $5(3.7)$ & $4(4.6)$ & $1(2.0)$ & & \\
\hline * Others & & $20(14.6)$ & $11(12.8)$ & $9(17.6)$ & & \\
\hline Times of eating a day & & & & & 12.6 & 0.002 \\
\hline Two & & $19(13.9)$ & $8(9.3)$ & $11(21.6)$ & & \\
\hline Three & & $98(71.5)$ & $59(68.6)$ & $39(78.0)$ & & \\
\hline Four or more & & $20(14.6)$ & $19(22.1)$ & $1(0.4)$ & & \\
\hline Meal skipping & & & & & 5.7 & 0.021 \\
\hline Yes & & $76(55.5)$ & $41(47.7)$ & $35(68.6)$ & & \\
\hline No & & $61(44.5)$ & $45(52.3)$ & $16(31.4)$ & & \\
\hline Type of meal skipped & & & & & 2.4 & 0.306 \\
\hline Breakfast & & $15(19.7)$ & $10(24.4)$ & $5(14.3)$ & & \\
\hline Lunch & & $57(75.0)$ & $30(73.2)$ & $27(77.1)$ & & \\
\hline Dinner & & $4(5.3)$ & $1(2.4)$ & $3(8.6)$ & & \\
\hline Total & & $76(100)$ & $41(53.9)$ & $35(46.1)$ & & \\
\hline Breakfast today & & & & & 0.3 & 0.627 \\
\hline Yes & & $116(84.7)$ & $74(86.0)$ & $42(82.4)$ & & \\
\hline No & & $21(15.3)$ & $12(14.0)$ & $9(17.6)$ & & \\
\hline Total & & $137(100)$ & $86(62.8)$ & $51(37.2)$ & & \\
\hline Snacking & & & & & 0.1 & 0.843 \\
\hline Yes & & $100(73.0)$ & $62(72.1)$ & $38(74.5)$ & & \\
\hline No & & $37(27.0)$ & $24(27.9)$ & $13(25.5)$ & & \\
\hline Total & & $137(100)$ & $86(62.8)$ & $51(37.2)$ & & \\
\hline
\end{tabular}

* Others: grandparent, aunt, uncle. Data are presented as frequency (percentage), mean, and standard deviation (SD). Pearson chi-square value is significant at $p<0.05$. 
$p<0.05)$, number of times of eating a day $\left(X^{2}=12.6\right.$, $p<0.05)$, and meal skipping $\left(X^{2}=5.7, p<0.05\right)$ had statistically significant relationship with the dietary iron intake (Table 1).

3.4. Principal Components of Iron Intake Patterns. Kaiser-Meyer-Olkin (0.53) and Bartlett's test of sphericity $(p<0.05)$ showed that the data was sufficient for factor analysis. Three factors (patterns) were retained from Cattell's scree plot. The loading factor of each dietary pattern constituent is shown in Table 2. The three patterns identified were named 'iron dietary pattern one', 'iron dietary pattern two,' and 'iron dietary pattern three'; unitedly, they explained $28.7 \%$ of the dietary iron intake variance (Table 2). Iron dietary pattern (DP) one (iron DP 1) explained $11.7 \%$ of the variance and was characterised by eggs, cocoyam leaves, turkey berries, dandelion, carrot, tangerine, pineapple, pawpaw, guava, pepper, tomato, coffee, soft drinks, sugarsweetened beverages, black tea, and chocolate. Iron dietary pattern two (iron DP 2) explained 9.9\% of the variance and comprised high consumption of meat, fish, poultry, egg, Amaranthus leaves, dandelion, moringa, oranges, lemon, with low intake of soft drinks, sugar-sweetened beverages, black tea, and chocolate. Iron dietary pattern three (iron DP 3) explained $7.1 \%$ of the variance and was composed of high intake of stinging nettle, coffee, soft drinks, sugar-sweetened beverages, with low intake of cocoyam leaves, turkey berries, pepper, and tomato.

Factor analysis (extraction method: principal component analysis; rotation method: varimax with Kaiser normalisation). Loading factor: \pm 0.3 . DP 1 : varying foods such as iron-rich, iron-enhancing, and iron-inhibiting foods; DP 2: iron-rich, iron-enhancing, and non-iron-inhibiting foods; DP 3: stinging nettle, iron-inhibiting foods, non-iron-enhancing foods, non-cocoyam leaves, and non-turkey berries.

3.5. Iron Status. Table 3 shows biochemical markers and dietary iron intake. Mann-Whitney $U$ test showed statistically significant $(p<0.05)$ relationship at haemoglobin level and ferritin level. Haemoglobin ( $\mathrm{Hb})$, ferritin, and C-reactive protein had median values of 11.8 (5.1-14.5), 43.0 (2.8-272.0), and 3,091.0 (1,030.0-7,420.0), respectively. Pearson chi-square test showed no statistically significant $(p>0.05)$ relationship in haemoglobin status and ferritin status. The study revealed that $70.6 \%$ of the adolescents had normal $\mathrm{Hb}$ and $29.4 \%$ had anaemia. Among the normal $\mathrm{Hb}$ group, $63.5 \%$ had adequate iron intake and $36.5 \%$ had inadequate dietary iron intake. Approximately $98 \%$ of the participants had normal ferritin. In the normal ferritin group, $36.7 \%$ had adequate dietary iron intake and $63.3 \%$ had inadequate intake. C-reactive protein levels of participants were normal with $62.6 \%$ having adequate dietary iron intake and $37.4 \%$ having inadequate intake.

3.6. Association between Patterns of Iron Intake and Serum Iron Status. After being adjusted for age and gender, partial correlation showed weak inverse and statistically significant
TABLE 2: Principal component analysis of dietary pattern (DP) of iron-rich food consumed.

\begin{tabular}{|c|c|c|c|}
\hline Food groups & DP1 & DP2 & DP3 \\
\hline \multicolumn{4}{|l|}{ Iron-rich } \\
\hline Meat & & 0.599 & \\
\hline Fish & & 0.665 & \\
\hline Poultry & & 0.373 & \\
\hline Egg & 0.344 & 0.349 & \\
\hline Cocoyam leaves & 0.321 & & -0.459 \\
\hline Turkey berries & 0.403 & & -0.497 \\
\hline Amaranthus leaves & & 0.408 & \\
\hline Stinging nettle & & & 0.332 \\
\hline Dandelion & 0.408 & 0.358 & \\
\hline Moringa & & 0.428 & \\
\hline Carrot & 0.318 & & \\
\hline \multicolumn{4}{|l|}{ Iron-Enhancing } \\
\hline Oranges & & 0.345 & \\
\hline Lemon & & 0.381 & \\
\hline Tangerine & 0.36 & & \\
\hline Pineapple & 0.468 & & \\
\hline Pawpaw & 0.356 & & \\
\hline Guava & 0.451 & & \\
\hline Pepper & 0.367 & & 0.349 \\
\hline Tomato & 0.488 & & 0.334 \\
\hline \multicolumn{4}{|l|}{ Iron-inhibiting } \\
\hline Coffee & 0.47 & & 0.378 \\
\hline Soft drinks & 0.469 & -0.305 & 0.567 \\
\hline Sugar-sweetened beverages & 0.51 & -0.433 & 0.433 \\
\hline Black tea & 0.343 & -0.438 & \\
\hline Chocolate & 0.48 & -0.415 & \\
\hline$\%$ variance & $11.70 \%$ & $9.90 \%$ & $7.10 \%$ \\
\hline$\%$ accumulated variance & $11.70 \%$ & $21.60 \%$ & $28.70 \%$ \\
\hline
\end{tabular}

relationship between dietary iron intake and iron DP 1 $(r=-0.234 * *, p<0.01)$, dietary iron intake and iron DP 2 $(r=-0.198 *, p<0.05)$, and iron DP 2 and vitamin C intake $(r=-0.201 *, p<0.05)$. Positive partial correlation and statistically significant relationship existed between dietary iron intake and dietary vitamin $\mathrm{C}$ intake $(r=0.520 * *, p<0.01)$. There was weak negative partial correlation between dietary iron intake and ferritin $(r=-0.124)$, and dietary iron intake and C-reactive protein $(r=-0.013)$ (Table 4).

Haemoglobin levels revealed weak and negative partial correlation, respectively, with iron DP $1(r=-0.075)$, iron DP $2(r=-0.086)$, and iron DP $3(r=-0.093)$. Haemoglobin levels showed weak positive partial relationship between dietary iron intake $(r=0.084)$ and vitamin $C(r=0.090)$, respectively. Ferritin and haemoglobin showed statistically significant and weak inverse correlation $(r=-0.200 *$, $p<0.05)$ (Table 4).

3.7. Predictors of Iron Status. Binary logistics regression showed that sociodemographic and dietary factors had insignificant relationship $(p>0.05)$ with haemoglobin status (Table 5). The odds of anaemia were nonsignificantly lower among male participants ( $\mathrm{OR}=0.6, \quad p=0.193,95 \%$ $\mathrm{CI}=0.3-1.3)$, guardians with formal education $(\mathrm{OR}=0.4$, $p=0.075,95 \% \mathrm{CI}=0.1-1.1)$, breakfast takers $(\mathrm{OR}=0.9$, $p=0.864,95 \% \mathrm{CI}=0.3-2.6)$, and participants with adequate 
TABLE 3: Biochemical markers and dietary iron intake.

\begin{tabular}{|c|c|c|c|c|c|c|c|}
\hline \multirow{2}{*}{ Total variables } & \multirow{2}{*}{ Median (min-max) } & \multirow{2}{*}{$p$ value } & \multirow{2}{*}{$N(\%)$} & \multicolumn{2}{|c|}{ Dietary iron intake } & \multirow{2}{*}{$X^{2}$} & \multirow{2}{*}{$p$ value } \\
\hline & & & & Adequate & Inadequate & & \\
\hline Haemoglobin & $11.8(5.1-14.5)$ & $<0.05$ & & & & 0.0 & 1.000 \\
\hline No anaemia & & & $96(70.6)$ & $61(63.5)$ & $35(36.5)$ & & \\
\hline Anaemia & & & $40(29.4)$ & $25(62.5)$ & $15(37.5)$ & & \\
\hline Ferritin & $43.0(2.8-272.0)$ & $<0.05$ & & & & 1.1 & 0.556 \\
\hline Low & & & $3(2.3)$ & $1(66.7)$ & $2(33.3)$ & & \\
\hline Normal & & & $128(97.7)$ & $47(36.7)$ & $81(63.3)$ & & \\
\hline C-reactive protein & $3091.0(1030.0-7420.0)$ & & & & & & \\
\hline Normal & & & $131(100)$ & $82(62.6)$ & $49(37.4)$ & & \\
\hline
\end{tabular}

Continuous nonparametric data are presented in median (minimum-maximum); Mann-Whitney U test; chi-square test; frequency (percentage); Fisher's exact. $p$ value is significant at $p<0.05$.

TABLe 4: Partial correlation of iron dietary pattern (IDP) and biochemical markers.

\begin{tabular}{|c|c|c|c|c|c|c|c|c|}
\hline \multirow{2}{*}{ Variables } & \multicolumn{3}{|c|}{ Iron } & \multirow{2}{*}{ Dietary iron } & \multirow{2}{*}{ Vitamin C } & \multirow{2}{*}{ Haemoglobin } & \multirow{2}{*}{ Ferritin } & \multirow{2}{*}{ C-protein } \\
\hline & DP 1 reactive & DP 2 & DP 3 & & & & & \\
\hline Iron DP 1 & 1.000 & -0.047 & 0.045 & $-0.234^{* *}$ & -0.080 & -0.075 & 0.099 & -0.005 \\
\hline Iron DP 2 & -0.047 & 1.000 & 0.030 & $-0.198^{*}$ & $-0.201^{*}$ & -0.086 & -0.075 & -0.081 \\
\hline Iron DP 3 & 0.045 & 0.030 & 1.000 & -0.080 & -0.087 & -0.093 & 0.014 & 0.055 \\
\hline Dietary iron & $-0.234^{* *}$ & $0.198^{*}$ & -0.080 & 1.000 & $0.520^{* *}$ & 0.084 & -0.123 & 0.010 \\
\hline Vitamin C & -0.080 & -0.201 & -0.087 & $0.520^{* *}$ & 1.000 & 0.090 & -0.015 & 0.053 \\
\hline Haemoglobin & -0.075 & -0.086 & -0.093 & 0.084 & 0.090 & 1.000 & $-0.178^{*}$ & -0.140 \\
\hline Ferritin & 0.099 & -0.075 & 0.014 & -0.123 & -0.015 & $-0.178^{*}$ & 1.000 & 0.100 \\
\hline C-reactive protein & -0.005 & -0.081 & 0.055 & 0.010 & 0.053 & -0.140 & 0.100 & 1.000 \\
\hline
\end{tabular}

Controlled variables: age and gender. ${ }^{*}$ Partial correlation is significant at the 0.05 level (2-tailed). ${ }^{* *}$ Partial correlation is significant at the 0.01 level (2-tailed). DP: dietary pattern.

TABLE 5: Binary logistic regression for predictors of anaemia.

\begin{tabular}{|c|c|c|c|}
\hline Predictors & $\beta$ & Anaemia OR (95\% CI) & $p$ value \\
\hline $\begin{array}{l}\text { SociodemographicsGen } \\
\text { Male } \\
\text { Female }\end{array}$ & der & $\begin{array}{c}0.6(0.3-1.3) \\
1\end{array}$ & 0.193 \\
\hline $\begin{array}{l}\text { Level of education } \\
\text { JHS } \\
\text { Primary }\end{array}$ & 0.544 & $\begin{array}{c}1.7(0.7-4.0) \\
1\end{array}$ & 0.213 \\
\hline $\begin{array}{l}\text { Guardian educational } \\
\text { Formal } \\
\text { Nonformal education }\end{array}$ & $\begin{array}{l}\text { status } \\
-0.944\end{array}$ & $\begin{array}{c}0.4(0.1-1.1) \\
1\end{array}$ & 0.075 \\
\hline $\begin{array}{l}\text { Dietary factors } \\
\text { Meal skipping } \\
\text { Yes } \\
\text { No }\end{array}$ & $\begin{array}{c}0.367 \\
1\end{array}$ & $1.4(0.7-3.0)$ & 0.328 \\
\hline $\begin{array}{l}\text { Breakfast } \\
\text { Yes } \\
\text { No }\end{array}$ & $\begin{array}{c}-0.090 \\
1\end{array}$ & $0.9(0.3-2.6)$ & 0.864 \\
\hline $\begin{array}{l}\text { Snacking } \\
\text { Yes } \\
\text { No } \\
\end{array}$ & $\begin{array}{c}0.484 \\
1 \\
\end{array}$ & $1.6(0.7-3.6)$ & 0.234 \\
\hline $\begin{array}{l}\text { Dietary iron intake } \\
\text { Adequate } \\
\text { Inadequate }\end{array}$ & $\begin{array}{c}-0.011 \\
1\end{array}$ & $1.0(0.5-2.1)$ & 0.977 \\
\hline $\begin{array}{l}\text { Dietary vitamin } C \text { into } \\
\text { Adequate } \\
\text { Inadequate }\end{array}$ & $\begin{array}{c}\text { ake } \\
-0.080 \\
1\end{array}$ & $0.9(0.2-5.0)$ & 0.926 \\
\hline
\end{tabular}

vitamin $\mathrm{C}$ intake $(\mathrm{OR}=0.9, p=0.926,95 \% \mathrm{CI}=0.2-5.0)$. Furthermore, the odds of anaemia were nonsignificantly higher among JHS participants (OR $=1.7, p=0.213,95 \%$ $\mathrm{CI}=0.7-4.0)$, meal skippers $(\mathrm{OR}=1.4, \quad p=0.328,95 \%$ $\mathrm{CI}=0.7-3.0)$, and adolescents who snacks $(\mathrm{OR}=1.6$, $p=0.234,95 \% \mathrm{CI}=0.7-3.6)$.

\section{Discussion}

The study identified patterns of dietary iron intake, iron status, and predictors of anaemia among early adolescents in a rural district in Ghana.

The application of principal component analysis (PCA) in the study identified three iron dietary patterns, namely, iron dietary pattern one, iron dietary pattern two, and iron dietary pattern three. All of the three iron dietary patterns were inversely related to haemoglobin levels and dietary iron intake. However, there was a significant relationship between dietary iron intake and iron dietary patterns one and two, respectively. Guardians with formal education, the number of times of eating a day, and meal skipping were significantly associated with dietary iron intake. Dietary iron intake was significantly related to dietary vitamin $\mathrm{C}$ intake. Male gender, a guardian with formal education, breakfast, and dietary vitamin $\mathrm{C}$ intake reduced the rate of anaemia occurrence; however, participants with JHS education, meal skipping, and snacking habit showed the contrary. All the 
sociodemographic and dietary factors showed no statistically significant relationship with the rate of anaemia.

Iron dietary pattern one was characterised by eggs, cocoyam leaves, turkey berries, dandelion, carrot, tangerine, pineapple, pawpaw, guava, pepper, tomato, coffee, soft drinks, sugar-sweetened beverages, coffee, black tea, and chocolate. Foods that constituted iron dietary pattern two were meat, fish, poultry, egg, Amaranthus leaves, dandelion, moringa, and less or no consumption of soft drinks, sugarsweetened beverages, black tea, and chocolate. Iron dietary pattern three comprised stinging nettle, coffee, soft drinks, sugar-sweetened beverages, and low intake of cocoyam leaves, turkey berries, pepper, and tomato. Participants with iron dietary pattern two consumed more of the haem iron sources compared to the other patterns. Iron dietary pattern one participants consumed more of the non-haem sources, iron-enhancing foods, and iron-inhibiting foods compared to iron dietary pattern two and three participants. Findings from iron dietary pattern one is consistent with other studies $[38,39]$. Frequent intake of iron-inhibiting foods in the iron dietary pattern one had a semblance of "western" and "unhealthy" dietary pattern identified in adolescents in Brazil and Republic of Ireland, respectively [40, 41]. Excessive consumption of non-haem iron food sources as the major sources of iron intake of dietary pattern one and two confirms most of the dietary intake studies in developing countries [15, 42, 43]. The inverse relationship between all the iron dietary patterns and haemoglobin and dietary iron intake may be related to limited consumption of iron-enhancing foods, high consumption of iron-inhibiting foods and non-haem iron sources, and weakness of the dietary survey method as it relies on memory and estimation. Significant relationship and weak inverse correlation between dietary iron intake and iron dietary patterns one and two are evidenced in increased similar intake of iron-rich foods and iron-enhancing foods in these patterns.

Dietary iron intake was statistically significant and positively associated with guardians with formal education and meal skipping. Most guardians are key kitchen persons, and since they could read and understand food labels, this might have encouraged the intake of iron-rich foods and iron-enhancing foods as shown in iron DP 1 and iron DP 2. A similar outcome has been shown in other studies $[44,45]$. However, a study reported that adolescents with guardians of less education had adequate dietary iron intake [46]. Meal skipping significantly reduced adequate dietary iron intake, which is consistent with other studies that found that meal skipping significantly reduced intake of iron, folate, calcium, sodium, and fibre $[47,48]$. On the contrary, higher vitamin C intake was identified in a disordered eating pattern among teenagers [49].

In this study, the majority of participants had adequate iron intake, and male gender had adequate dietary iron intake, thus showing a positive association with low anaemia prevalence, which has also been reported in other studies $[4,50-53]$. Low rate of anaemia in participants with guardians of formal education confirms the role of education in alleviating anaemia [54-57]. The educated guardians could read and understand, hence influencing their children to make healthy and informed choices of food. The present study concurred with other findings that intake of breakfast increased the possibility of normal haemoglobin levels $[34,58]$. A study revealed that 'traditional breakfast' intake significantly influenced micronutrients intake [59]. Adequate vitamin $\mathrm{C}$ intake may have helped boost immunity, reduced infections, and enhanced iron absorption, being thus positively associated with high haemoglobin levels. Findings about this effect have been reported in a scientific study [60]. The present study reveals that inadequate dietary iron intake by females, in addition to menarche and menstrual blood loss, might have resulted in low haemoglobin levels [31]. Inadequate dietary iron intake was also observed among European adolescent girls [61]. The current study adds to several others that revealed high levels of anaemia in female participants due to similar factors [62-64].

Meal skipping was popular among our study population as seen in most studies [65-68]. Breakfast and dinner were skipped; however, lunch was the most skipped meal as has been reported in other scientific studies [67, 69]. The present study shows that meal skipping was related to an inadequate iron intake which concurs with previous studies that showed that meal skipping contributed to poor micronutrient intake in adolescents $[33,56,66]$. The current study shows that meal skipping was highly associated with anaemia due to inadequate intake of iron-rich and iron-enhancing foods as seen in iron DP 3. Participants at JHS level showing a high rate of anaemia may be due to meal skipping, having guardians with nonformal education, and excessive consumption of iron-inhibiting foods exhibited in iron dietary patterns one and three. This finding contradicts the outcome of other studies [70, 71]. Increased snacking showed high inadequate dietary iron intake, and it was consistent with high rate of low haemoglobin levels as most participants reported consuming soft drinks, popcorn, cocoa tea, biscuits, toffees, ice cream, and plantain chips. Similar choices of snacking were found in adolescents living in other developing countries $[72,73]$. Snacking is a recipe for poor dieting in adolescent [74]. It was also evident in the iron dietary pattern one as most of the participants consumed all the varieties of iron-inhibiting foods.

All the participants had normal C-reactive protein levels with the majority having normal ferritin and haemoglobin levels. C-reactive protein showed a weak inverse relationship with haemoglobin. Dietary iron and vitamin C consumption had a positive moderate correlation and statistically significant relationship. Our result shows that participants with dietary iron and vitamin $\mathrm{C}$ intake had a weak positive correlation with haemoglobin levels, confirming other scientific findings $[75,76]$. Moreover, these factors had a negative association with anaemia. It may be possible that most of these participants belong to iron dietary pattern two as high consumption of haem iron and iron-enhancing food was seen in this pattern. The study outcome appears to support the recommendation of encouragement of dietary iron intake and vitamin $\mathrm{C}$ to enhance haemoglobin levels [77]. Ferritin showed a weak inverse correlation with dietary iron and vitamin $\mathrm{C}$ intake. This may be due to inadequate intake of foods rich in iron and vitamin $\mathrm{C}$, as seen in iron DP 
3, and high consumption of iron-inhibiting and non-haem iron foods, as demonstrated in iron DP 1. Plant sources of iron have low bioavailability, whereas haem iron is shown to be a better predictor of serum ferritin in an Australian population study $[78,79]$.

\section{Conclusion}

The iron dietary patterns showed a high intake of non-haem iron and iron-inhibiting foods. Meal skipping, guardians with formal education, and times of eating a day were significantly related to dietary iron intake. Meal skipping, snacking, and adolescents with JHS education were more associated with low haemoglobin levels.

\section{Data Availability}

The data used to support the findings of this study could be assessed by writing to the Chairman Committee on Human Research Publication Ethics, Room 8 Anatomy Block 3, School of Medical Sciences, Kwame Nkrumah University of Science and Technology, Kumasi, Ghana, or chrpe.knust.kath@gmail.com.

\section{Conflicts of Interest}

The authors declare that they have no conflicts of interest.

\section{Authors' Contributions}

Michael Akenteng Wiafe designed and implemented the study and wrote the manuscript. Charles Apprey carried out statistical analysis and reviewed and provided an input to the manuscript. Reginald Adjetey Annan designed the study, performed statistical analysis, and reviewed the manuscript. All authors read and approved the final manuscript.

\section{Acknowledgments}

We are grateful to Lawrence Dolyen Yamba, Godwin OpokuAgyemang, Nancy Elizabeth Tandoh, Anita Benewa, Odeafo Asamoah-Boakye, Edward Ato Abban, and Frank Agyemang Bonsu for their support in data collection and laboratory analysis. We acknowledge the adolescents and guardians who participated in the study. Financial support from Ghana National Petroleum Corporation is also acknowledged.

\section{References}

[1] World Health Organization, Orientation Programme on Adolescent Health for Health Care Providers, World Health Organization, Geneva, Switzerland, 2006.

[2] World Health Organization, Towards Adulthood: Exploring the Sexual and Reproductive Health of Adolescents in South Asia, World Health Organization, Geneva, Switzerland, 2003.

[3] R. Ranjan, U. P. Sahu, and A. K. Chaudhary, "Iron, vitamin B12 and folate deficiency in adolescents havingnutritional anaemia: a hospital-based study," IOSR Journal of Dental and Medical Sciences, vol. 17, pp. 15-17, 2018.

[4] S. K. Soman, B. Areekal, A. J. Murali, and R. G. Varghese, "Adolescent anaemia its prevalence and determinants: a cross-sectional study from south Kerala, India," International Journal Of Community Medicine And Public Health, vol. 4, no. 8, pp. 2750-2756, 2017.

[5] D. L. Sekhar, L. E. Murray-Kolb, A. R. Kunselman, C. S. Weisman, and I. M. Paul, "Association between menarche and iron deficiency in non-anemic young women," PLoS ONE, vol. 12, no. 5, Article ID e0177183, 2017.

[6] P. G. Bansal, G. S. Toteja, N. Bhatia et al., "Deficiencies of serum ferritin and vitamin B," International Journal for Vitamin and Nutrition Research, vol. 85, no. 1-2, pp. 14-22, 2015.

[7] G. C. Patton, C. A. Olsson, V. Skirbekk et al., "Adolescence and the next generation," Nature, vol. 554, no. 7693, pp. 458-466, 2018.

[8] S. L. Robinson, C. Marín, H. Oliveros et al., "Iron deficiency, anemia, and low vitamin B-12 serostatus in middle childhood are associated with behavior problems in adolescent boys: results from the bogotá school children cohort," The Journal of Nutrition, vol. 148, no. 5, pp. 760-770, 2018.

[9] J. R. Doom, B. Richards, G. Caballero, J. Delva, S. Gahagan, and B. Lozoff, "Infant iron deficiency and iron supplementation predict adolescent internalizing, externalizing, and social problems," The Journal of Pediatrics, vol. 195, pp. 199-205.e2, 2018.

[10] A. Gupta, Nutritional Anemia in Preschool Children, Springer, Berlin, Germany, 2017.

[11] S. O. Mousa, A. M. Higazi, S. M. Saleh, and H. A. Ali, "Cognitive function and school achievement in adolescent Egyptian girls with iron deficiency and iron deficiency anaemia," Mental Health in Family Medicine, vol. 12, pp. 289-294, 2016.

[12] M. Domellöf, I. Thorsdottir, and K. Thorstensen, "Health effects of different dietary iron intakes: a systematic literature review for the 5th Nordic Nutrition Recommendations," Food \& Nutrition Research, vol. 57, no. 1, Article ID 21667, 2013.

[13] M. Mesías, I. Seiquer, and M. P. Navarro, "Iron nutrition in adolescence," Critical Reviews in Food Science and Nutrition, vol. 53, no. 11, pp. 1226-1237, 2013.

[14] M. Samaniego-Vaesken, T. Partearroyo, J. Olza et al., "Iron intake and dietary sources in the Spanish population: findings from the ANIBES study," Nutrients, vol. 9, no. 3, p. 203, 2017.

[15] L. Korkalo, R. Freese, G. Alfthan, L. Fidalgo, and M. Mutanen, "Poor micronutrient intake and status is a public health problem among adolescent Mozambican girls," Nutrition Research, vol. 35, no. 8, pp. 664-673, 2015.

[16] S. Ochola and P. K. Masibo, "Dietary intake of schoolchildren and adolescents in developing countries," Annals of Nutrition and Metabolism, vol. 64, no. s2, pp. 24-40, 2014.

[17] I. Alaunyte, V. Stojceska, A. Plunkett, and E. Derbyshire, "Dietary iron intervention using a staple food product for improvement of iron status in female runners," Journal of the International Society of Sports Nutrition, vol. 11, no. 1, p. 50, 2014.

[18] World Health Organization, Worldwide Prevalence of Anaemia 1993-2005: WHO Global Database on Anaemia, World Health Organization, Geneva, Switzerland, 2008.

[19] A. S. A. Sharourou, M. A. Hassan, M. B. Teclebrhan, H. M. Alsharif, S. A. Alhamad, and T. S. Alsinani, "Anemia :its prevalence, causes and management," The Egyptian Journal of Hospital Medicine, vol. 70, no. 10, pp. 1877-1879, 2018.

[20] B. Chalise, K. K. Aryal, R. K. Mehta et al., "Prevalence and correlates of anemia among adolescents in Nepal: findings from a nationally representative cross-sectional survey," PLoS ONE, vol. 13, no. 12, Article ID e0208878, 2018. 
[21] L. Gosdin, K. Tripp, A. B. Mahama et al., "Predictors of anaemia among adolescent school children of Ghana," Journal of Nutritional Science, vol. 9, 2020.

[22] S. M. Sawyer, R. A. Afifi, L. H. Bearinger et al., "Adolescence: a foundation for future health," The Lancet, vol. 379, no. 9826, pp. 1630-1640, 2012.

[23] P. East, E. Delker, B. Lozoff, J. Delva, M. Castillo, and S. Gahagan, "Associations among infant iron deficiency, childhood emotion and attention regulation, and adolescent problem behaviors," Child Development, vol. 89, no. 2, pp. 593-608, 2018.

[24] S. More, V. B. Shivkumar, N. Gangane, and S. Shende, "Effects of iron deficiency on cognitive function in school going adolescent females in rural area of central India," Anemia, vol. 2013, Article ID 819136, 5 pages, 2013.

[25] L. Alizadeh, A. Raoofi, L. Salehi, and M. Ramzi, "Impact of maternal hemoglobin concentration on fetal outcomes in adolescent pregnant women," Iranian Red Crescent Medical Journal, vol. 16, no. 8, 2014.

[26] D. Skolmowska and D. Głabska, "Analysis of heme and nonheme iron intake and iron dietary sources in adolescent menstruating females in a national polish sample," Nutrients, vol. 11, no. 5, p. 1049, 2019.

[27] E. S. Sumarlan, E. Windiastuti, and H. Gunardi, "Iron status, prevalence and risk factors of iron deficiency anemia among 12-to 15-year-old adolescent girls from different socioeconomic status in Indonesia," Makara Journal of Health Research, vol. 22, no. 1, p. 8, 2018.

[28] F. Hassan, S. Salim, and A. Humayun, "Prevalence and determinants of iron deficiency Anemia in adolescents girls of low income communities in Lahore," Annals of King Edward Medical University, vol. 23, no. 2, 2017.

[29] A. Srivastava, R. Kumar, and M. Sharma, "Nutritional anaemia in adolescent girls: an epidemiological study," International Journal of Community Medicine And Public Health, vol. 3, no. 4, pp. 808-812, 2017.

[30] B. Patavegar, N. Rasheed, R. Pathak, M. Kapilashrami, and A. Farookee, "Menstrual pattern and menstrual disorders among school-going adolescent girls in Delhi," Journal of Basic and Applied Research International, vol. 11, no. 4, pp. 241-246, 2015.

[31] D. I. Tayel and S. Ezzat, "Anaemia and its associated factors among adolescents in Alexandria, Egypt," International Journal of Health Sciences and Research (IJHSR), vol. 5, pp. 260-271, 2015.

[32] A. Sjöberg and L. Hulthén, "Comparison of food habits, iron intake and iron status in adolescents before and after the withdrawal of the general iron fortification in Sweden," $E$ ropean Journal of Clinical Nutrition, vol. 69, no. 4, p. 494, 2015.

[33] A. Otuneye, P. Ahmed, A. Abdulkarim, O. Aluko, and D. Shatima, "Relationship between dietary habits and nutritional status among adolescents in Abuja municipal area council of Nigeria," Nigerian Journal of Paediatrics, vol. 44, no. 3, pp. 128-135, 2017.

[34] R. N. B. Ayogu, A. M. Okafor, and H. N. Ene-Obong, "Iron status of schoolchildren (6-15 years) and associated factors in rural Nigeria," Food \& Nutrition Research, vol. 59, no. 1, Article ID 26223, 2015.

[35] M. Tesfaye, T. Yemane, W. Adisu, Y. Asres, and L. Gedefaw, "Anaemia and iron deficiency among school adolescents: burden, severity, and determinant factors in southwest Ethiopia," Adolescent Health Medicine and Therapeutics, vol. 6, pp. 189-196, 2015.
[36] R. C. De Andrade Cairo, L. R. Silva, N. C. Bustani, and C. D. F. Marques, "Iron deficiency anemia in adolescents; a literature review," Nutrición Hospitalaria, vol. 29, no. 6, pp. 1240-1249, 2014.

[37] J. J. Otten, J. P. Hellwig, and L. D. Meyers, Dietary Reference Intakes: The Essential Guide to Nutrient Requirements, Institute of Medicine, Washington, NJ, USA, 2006.

[38] M. C. Afeiche, L. S. Taillie, S. Hopkins, A. L. Eldridge, and B. M. Popkin, "Breakfast dietary patterns among Mexican children are related to total-day diet quality," The Journal of Nutrition, vol. 147, no. 3, pp. 404-412, 2017.

[39] V. Mikkilä, H. Vepsäläinen, T. Saloheimo et al., “An international comparison of dietary patterns in 9-11-year-old children," International Journal of Obesity Supplements, vol. 5, no. 2, pp. S17-S21, 2015.

[40] R. D. C. Ribeiro-Silva, R. L. Fiaccone, M. E. P. D. ConceiçãoMachado, A. S. Ruiz, M. L. Barreto, and M. L. P. Santana, "Body image dissatisfaction and dietary patterns according to nutritional status in adolescents," Jornal de pediatria, vol. 94, no. 2, pp. 155-161, 2018.

[41] Á. P. Hearty and M. J. Gibney, "Dietary patterns in Irish adolescents: a comparison of cluster and principal component analyses," Public Health Nutrition, vol. 16, no. 5, pp. 848-857, 2013.

[42] D. Gashu, B. J. Stoecker, A. Adish, G. D. Haki, K. Bougma, and G. S. Marquis, "Ethiopian pre-school children consuming a predominantly unrefined plant-based diet have low prevalence of iron-deficiency anaemia," Public Health Nutrition, vol. 19, no. 10, pp. 1834-1841, 2016.

[43] A. C. Roba, K. Gabriel-Micheal, G. A. Zello, J. Jaffe, S. J. Whiting, and C. J. Henry, "A low pulse food intake may contribute to the poor nutritional status and low dietary intakes of adolescent girls in rural southern Ethiopia," Ecology of Food and Nutrition, vol. 54, no. 3, pp. 240-254, 2015.

[44] H. J. Choi, H. J. Lee, H. B. Jang et al., "Effects of maternal education on diet, anaemia, and iron deficiency in Korean school-aged children," BMC Public Health, vol. 11, no. 1, p. 870, 2011.

[45] T. D. Wachs, H. Creed-Kanashiro, S. Cueto, and E. Jacoby, "Maternal education and intelligence predict offspring diet and nutritional status," The Journal of Nutrition, vol. 135, no. 9, pp. 2179-2186, 2005.

[46] C. Thongprasert, C. Hutchinson, W. Satheannoppakao, and M. Tipayamongkholgul, "Dietary iron intake and availability are related to maternal education level in overweight/obese adolescents," European Journal of Nutrition, vol. 57, no. 6, pp. 2249-2260, 2018.

[47] S. A. Ramsay, T. D. Bloch, B. Marriage, L. H. Shriver, C. K. Spees, and C. A. Taylor, "Skipping breakfast is associated with lower diet quality in young US children," European Journal of Clinical Nutrition, vol. 72, no. 4, pp. 548-556, 2018.

[48] K. C. Mathias, E. Jacquier, and A. L. Eldridge, "Missing lunch is associated with lower intakes of micronutrients from foods and beverages among children and adolescents in the United States," Journal of the Academy of Nutrition and Dietetics, vol. 116, no. 4, pp. 667-676, 2016.

[49] L. G. Caran, D. D. Santana, L. S. Monteiro, and G. V. Da Veiga, "Disordered eating behaviors and energy and nutrient intake in a regional sample of Brazilian adolescents from public schools," Eating and Weight Disorders-Studies on Anorexia, Bulimia and Obesity, vol. 23, no. 6, pp. 825-832, 2018.

[50] S. M. Awaluddin, N. A. Ahmad, B. M. Naidu, M. S. Mohamad, and M. Yusof, "A population-based anaemia screening using 
point-of-care in estimating prevalence of anaemia in Malaysian adults: findings from a nationwide survey," Journal of Community Medicine and Health Education, vol. 7, p. 513, 2017.

[51] R. Debbarma, P. Paul, B. Debbarma, T. Sutnga, and B. Loukakpam, "Anaemia among medical students of regional institute of medical sciences (RIMS)," Scholars Journal of Applied Medical Sciences, vol. 4, pp. 3744-3748, 2016.

[52] A.-J. M. Alquaiz, T. A. Khoja, A. Alsharif et al., "Prevalence and correlates of anaemia in adolescents in Riyadh city, Kingdom of Saudi Arabia," Public Health Nutrition, vol. 18, no. 17 , pp. 3192-3200, 2015.

[53] K. Mehta, "Prevalence of nutritional anaemia among college students and its correlation with their body mass index," International Journal of Scientific Research, vol. 4, no. 3, pp. 1882-1886, 2015.

[54] A. Khan, R. K. Chawla, C. Wang, and M. Guo, "Risk factors associated with anaemia among adolescent girls: a crosssectional study in District Peshawar, Pakistan," Journal of Pakistan Medical Association, vol. 69, no. 11, pp. 1591-1595, 2019.

[55] K. L. Harding, V. M. Aguayo, W. A. Masters, and P. Webb, "Education and micronutrient deficiencies: an ecological study exploring interactions between women's schooling and children's micronutrient status," BMC Public Health, vol. 18, no. 1, p. $470,2018$.

[56] Z. Getaneh, B. Enawgaw, G. Engidaye et al., "Prevalence of anemia and associated factors among school children in Gondar town public primary schools, northwest Ethiopia: a school-based cross-sectional study," PLoS One, vol. 12, no. 12, Article ID e0190151, 2017.

[57] I. Achouri, Y. Aboussaleh, R. Sbaibi, A. Ahami, and M. E. Hioui, "Prevalence of iron deficiency anaemia among school children in Kenitra, Northwest of Morocco," Pakistan Journal of Biological Sciences, vol. 18, no. 4, p. 191, 2015.

[58] B. Soi, L. J. Utama, and J. G. L. Sine, "December. Breakfast habits and it,'s relation to nutritional status and anemia among elementary school children," in Proceeding of the 1st. International Conference Health Polytechnic of Kupang, pp. 439-448, Kupang, Indonesian, November 2018.

[59] A. Jeyakumar and P. Ghugre, "Is lack of breakfast contributing to nutrient deficits and poor nutritional indicators among adolescent girls?" Nutrition and Health, vol. 23, no. 3, pp. 177-184, 2017.

[60] A. Singh, K. Bains, and H. Kaur, "Relationship of dietary factors with dialyzable iron and in vitro iron bioavailability in the meals of farm women," Journal of Food Science and Technology, vol. 53, no. 4, pp. 2001-2008, 2016.

[61] S. Vandevijvere, N. Michels, N. Michels et al., "Intake and dietary sources of haem and non-haem iron among European adolescents and their association with iron status and different lifestyle and socio-economic factors," European Journal of Clinical Nutrition, vol. 67, no. 7, pp. 765-772, 2013.

[62] R. K. Campbell, V. M. Aguayo, Y. Kang et al., "Epidemiology of anaemia in children, adolescent girls, and women in Bhutan," Maternal \& Child Nutrition, vol. 14, Article ID e12740, 2018.

[63] D. Anand and R. K. Anuradha, "Malnutrition status of adolescent girls in India: a need for the hour," International Journal of Scientific Research, vol. 5, pp. 642-646, 2016.

[64] W. Y Gan, M. T. N. Mohd, M. S. Zalilah, and A. S. Hazizi, "Differences in eating behaviours, dietary intake and body weight status between male and female Malaysian University students," Malaysian Journal of Nutrition, vol. 17, no. 2, pp. 213-228, 2011.
[65] M. O. Sönmez and F. Nazik, "Changing nutrition habits: snack consumption, meal skipping and anthropometric parameters of university students in Turkey," Southeast Asian Journal of Tropical Medicine and Public Health, vol. 50, no. 1, pp. 180-190, 2019.

[66] A. C. Medin, J. B. Myhre, L. M. Diep, and L. F. Andersen, "Diet quality on days without breakfast or lunch - identifying targets to improve adolescents' diet," Appetite, vol. 135, pp. 123-130, 2019.

[67] R. Kelishadi, N. Mozafarian, M. Qorbani et al., "Is snack consumption associated with meal skipping in children and adolescents? The CASPIAN-IV study," Eating and Weight Disorders-Studies on Anorexia, Bulimia and Obesity, vol. 22, no. 2, pp. 321-328, 2017.

[68] T. H. Stea, F. N. Vik, E. Bere, M. V. Svendsen, and I. M. Oellingrath, "Meal pattern among Norwegian primaryschool children and longitudinal associations between meal skipping and weight status," Public Health Nutrition, vol. 18, no. 2, pp. 286-291, 2015.

[69] J. L. Krok-Schoen, S. S. Jonnalagadda, M. Luo, O. J. Kelly, and C. A. Taylor, "Nutrient intakes from meals and snacks differ with age in middle-aged and older Americans," Nutrients, vol. 11, no. 6, p. 1301, 2019.

[70] E. Z. Tariku, G. A. Abebe, Z. A. Melketsedik et al., “Anaemia and its associated factors among school-age children living in different climatic zones of Arba Minch Zuria District, Southern Ethiopia," BMC Haematology, vol. 19, no. 1, p. 6, 2019.

[71] G. M. Abdel-Rasoul, R. E. El Bahnasy, H. M. El Shazly, H. M. Gabr, and N. B. Abdel-Aaty, "Epidemiology of irondeficiency anaemia among primary school children (6-11 years), Menoufia governorate, Egypt," Menoufia Medical Journal, vol. 28, no. 3, p. 663, 2015.

[72] E. Keats, A. Rappaport, S. Shah, C. Oh, R. Jain, and Z. Bhutta, "The dietary intake and practices of adolescent girls in lowand middle-income countries: a systematic review," Nutrients, vol. 10, no. 12, p. 1978, 2018.

[73] C. M. Nguu-Gutu, J. K. Imungi, and E. M. Ngatia, Snacking and Dietary Intake of Protein and Energy by High School Adolescents in Nairobi, pp. 35-49, University of Nairobi, Nairobi, Kenya, 2017.

[74] N. I. Larson, J. M. Miller, A. W. Watts, M. T. Story, and D. R. Neumark-Sztainer, "Adolescent snacking behaviors are associated with dietary intake and weight status," The Journal of Nutrition, vol. 146, no. 7, pp. 1348-1355, 2016.

[75] E. Aritonang and A. Siagian, "Relation between food consumption and anemia in children in primary school in a final disposal waste area," Pakistan Journal of Nutrition, vol. 16, no. 4, pp. 242-248, 2017.

[76] A. Abriha, M. Yesuf, and M. Wassie, "Prevalence and associated factors of anemia among pregnant women of Mekelle town: a cross sectional study," BMC Research Notes, vol. 7, no. 1, p. $888,2014$.

[77] S. Anschuetz, C. D. Rodgers, and A. W. Taylor, "Meal composition and iron status of experienced male and female distance runners," Journal of Exercise Science \& Fitness, vol. 8, no. 1, pp. 25-33, 2010.

[78] I. Young, H. Parker, A. Rangan et al., "Association between haem and non-haem iron intake and serum ferritin in healthy young women," Nutrients, vol. 10, no. 1, p. 81, 2018.

[79] R. Hurrell and I. Egli, "Iron bioavailability and dietary reference values," The American Journal of Clinical Nutrition, vol. 91, no. 5, pp. 1461S-1467S, 2010. 